\title{
Strategies to Fight Stigma toward People with Mental Disorders: Perspectives from Different Stakeholders
}

\author{
Marc Corbière, ${ }^{1}$ Esther Samson, ${ }^{1,2}$ Patrizia Villotti, ${ }^{3}$ and Jean-François Pelletier ${ }^{4,5}$ \\ ${ }^{1}$ School of Rehabilitation, Université de Sherbrooke, and Centre for Action in Work Disability Prevention and Rehabilitation, \\ 150 Place Charles LeMoyne, Longueuil, QC, Canada J4K 0A8 \\ ${ }^{2}$ Association Québécoise pour la Réadaptation Psychosociale, 2380 Avenue du Mont-Thabor, Bureau 205, Québec, \\ QC, Canada G1J 3W7 \\ ${ }^{3}$ Department of Cognitive Sciences and Education, University of Trento, Matteo del Ben 5, 38068 Rovereto, Italy \\ ${ }^{4}$ Département de Psychiatrie, Centre de Recherche Fernand-Seguin, Hôpital Louis-H. Lafontaine, Université de Montréal, \\ 7401 Rue Hochelaga, Montréal, QC, Canada H1N $3 M 5$ \\ ${ }^{5}$ Department of Psychiatry, Yale Program for Recovery \& Community Health, Yale University School of Medicine, Erector Square, \\ Building One, 319 Peck Street, New Haven, CT 06513, USA
}

Correspondence should be addressed to Marc Corbière, marc.corbiere@usherbrooke.ca

Received 6 August 2012; Accepted 13 September 2012

Academic Editors: E. Broekaert, R. C. Rapp, W. Vanderplasschen, and S. Vandevelde

Copyright (C) 2012 Marc Corbière et al. This is an open access article distributed under the Creative Commons Attribution License, which permits unrestricted use, distribution, and reproduction in any medium, provided the original work is properly cited.

\begin{abstract}
This study aims to provide a more complete and exhaustive perspective on the whole range of potential strategies to fight stigma by considering the perspectives of different stakeholders. Delegates to a Canadian conference were invited to participate in a survey that focused on stigma, from which the responses to the following question were analyzed: tell us briefly what you do to reduce prejudice and stigma toward people with a diagnosis of mental disorder? From 253 participants, 15 categories of strategies to fight stigma were identified from the verbatim (e.g., sharing/encouraging disclosure). These categories fell under six main themes: education, contact, protestation, person centered, working on recovery and social inclusion, and reflexive consciousness. The occurrence of these themes was different among stakeholders (clinical, organizational, and experiential knowledge). For example, people with mental disorders (experiential knowledge) often mentioned contact and person centered strategies, while mental health professionals (clinical knowledge) preferred education and working on recovery and social inclusion strategies. The results from this study highlight the need to pay more attention to the concept of disclosure of mental disorders in the process for de-stigmatization. Future studies are needed to assess the impact of the emerging strategies to fight stigma in the community.
\end{abstract}

\section{Introduction}

Much has been written about stigma and how it applies to people with severe mental illness [1-3]. Stigma is a complex term defined as a visible or invisible attribute, deeply discrediting, that disqualifies its bearer from full social acceptance, often resulting in several forms of discrimination [4]. Today, stigma is described as "a severe social disapproval due to believed or actual individual characteristics, beliefs or behaviors that are against norms, be they economic, political, cultural or social" [5, p. 10]. It is characterized by a lack of knowledge about mental health, fear, prejudgment, and discrimination. In its most advanced forms, stigma leads to exclusion of the person from several spheres of social functioning and it causes feelings of guilt, shame, inferiority, and a wish for concealment [6].

Stigma toward people with mental disorders is a complex issue with the capacity to affect all facets of a person's life, such as the opportunity to find housing and employment, enter higher education, obtain insurance, and get fair treatment in the criminal justice or child welfare systems $[7,8]$. Thus, stigma robs people with mental illness of particularly important life opportunities vital to achieving life goals, obtaining competitive employment, and living independently in a safe and comfortable home [9].

Stigmatization toward people with mental disorders stems from different stakeholders in the community and can be expressed differently, considering these perspectives, 
sometimes resulting in self-stigmatization. Evans and Repper [10] reported that the general tendency for employers and mental health professionals is to underestimate the capacities and skills of people with mental illness: these behaviors, to a certain extent, can be experienced as discriminating. Lack of interest in the person's background and needs and exclusion of relatives from treatment planning have also been mentioned as professionals' stigmatizing attitudes toward people with mental illness $[11,12]$. It has also been argued that mental health professionals can sometimes hold the same public stigmatizing attitudes toward mentally ill individuals as well as very pessimistic views of their chances of recovery [8]. Stigmatizing attitudes have also been observed among students from many segments of medical and psychological services [13]. An additional issue is that some people with mental illness endorse stigmatizing attitudes about psychiatric disability, starting to believe that he/she deserves to be treated in such a way. The internalized stigma affects the individual's self-perception and can potentially impact success or failure in life opportunities, such as employment. This serves to reinforce the negative stereotypes and social exclusion associated with severe mental illnesses [14]. Thus, self-stigma leads people with mental illness and their families to adopt attitudes of self-loathing and self-blame, resulting in a sense of helplessness and hopelessness [8].

More than 40 negative consequences of stigma have been reported in the literature $[15,16]$. While the damaging impact of stigma is mainly confined to the stigmatized individual, public stigma also impacts their families and close friends, who can experience high levels of shame and embarrassment [17]. This is what has been called the "courtesy of stigma", meaning the result of being related to a person with a stigma $[4,11,18]$. In general, everyone who comes into close contact with the mentally ill, such as mental health support groups and even mental health professionals $[4,13,19,20]$, suffers from their own type of public stigma. For example, a psychiatrist's authority has been considered inferior to other medical experts, so patients often ignore their advice and, therefore, they frequently appear ineffective [21].

In sum, stigma can severely and negatively impact mentally ill individuals, their families, and service providers in a number of ways. Due to stigma's devastating effects, studies worldwide have recently aimed to raise awareness and understanding about the most effective strategies to combat stigma and discrimination. Little is known about how to combat stigmatizing attitudes toward people with mental illness and the ingredients for successful antistigma activities $[18,22]$. The literature identifies three general approaches for countering stigmatizing attitudes and discriminating behavior associated with mental illness. These are education, contact, and protest $[23,24]$. Although each of these stigmareducing approaches has some degree of validity on the surface, they are not uniformly effective [25].

The first strategy to fight stigma originates from the belief that stigma is related to poor factual knowledge about mental illness and seeks to inform the general public and health professionals by replacing inaccurate stereotypes and false assumptions of mental illness with facts and accurate conceptions about the illness $[24,26]$. The limitations of this kind of intervention are that many stereotypes are resilient to change [27], and it has been argued that education modifies literacy and, sometimes, attitudes, but rarely behavior [18].

The second strategy aims to change negative attitudes toward the mentally ill through direct interactions with affected persons. Direct and face-to-face interactions are examples of contact interventions [28]. Contact appears to be the most promising strategy for reducing stigma [27], especially when contact is one-on-one: when people are seen as having equal status and when people are working together in a cooperative rather than competitive manner [29-31]. However, reducing stigma through contact is timeconsuming and may not be cost efficient [32]. Also, the efficacy of this strategy seems to depend on the context and the nature of the contact.

The third strategy works on conveying messages to report and to believe reported negative and inaccurate representations of mental illness. Advocacy activities, educational support groups, and patient empowerment groups are examples of interventions within the protest strategy. This kind of strategy is usually effective in diminishing negative attitudes about mental illness but it fails to promote more positive attitudes supported by facts. Also, a rebound effect may occur and can be observed in the stigmatizing beliefs of the public $[24,27]$, meaning that protest does not necessarily change people's prejudice about mental illness.

The challenge of combating stigma is still prominent in the mental health field and much more needs are to be done. The fight against stigma is a complex endeavor, with multifaceted implications, and must be examined from multiple perspectives (e.g., mentally ill individuals, their families, and healthcare professionals) to increase knowledge and experience about the best strategies for antistigma campaigns. Until now, few studies focusing on the perspective of those having mental illness, relatives or mental health practitioners, have been published and there is a paucity of research using everyday life settings for examining strategies to fight stigma. Most efforts have focused on directly improving community attitudes even though it seems relevant that antistigma programs would also address patients and their relatives. Studies conducted in this manner reported few suggestions, which were mainly concerned with improving information on mental health issues for the public $[12,19]$.

The main objective of this study is to provide an exhaustive perspective on the whole range of strategies to fight stigma used by different stakeholders, such as mentally ill individuals, their families, mental health professionals, and other people working in mental health organizations. The intent is to focus on everyday and practical strategies that can, ideally, be applied across various settings, such as health, community, workplace, and school. More particularly, specific objectives aim to (1) produce emerging strategies to fight stigma that consider the perspectives of different stakeholders groups; (2) compare the occurrence of different types of strategies to fight stigma according to different types of knowledge: organizational (i.e., directors, managers, or coordinators working in the field of mental 
health), clinical (i.e., mental health professionals and/or clinicians), and experiential knowledge (i.e., users of mental health services).

\section{Methodology}

2.1. Procedure. In November 2010, the Quebec Association for Psychosocial Rehabilitation (AQRP) held its fifteenth conference entitled: "Overcoming Stigma, a Collective Challenge!”. This event brought together over 800 delegates from the public and community sectors of mental health (people who use mental health services, professionals, researchers, managers, etc.). The main objective of this event was to promote collective reflection on the consequences of stigmatization or destigmatization toward people with a mental disorder. As part of this conference, another objective was to enable understanding and familiarization of approaches, actions, resources, and strategies to overcome stigma and promote destigmatization.

At the beginning of the event, the conference delegates were invited to participate in a survey that focused on stigma (see below for a description). The survey invitation was delivered by direct contact: located in strategic areas and at appropriate times (mainly on the first day, during registration and breaks); volunteers invited delegates to a room reserved for data collection. The survey could be answered online (online survey created with SurveyMonkey) or on paper. The survey was approved by the ethics committee of the Universite de Sherbrooke.

2.2. Survey Description. The questionnaire was developed by a subgroup of the scientific committee of the fifteenth conference of the AQRP. The survey was composed, in part, of a series of questions (Likert scale) from an existing questionnaire. (The questionnaire is found in an ongoing project: Study of Factors Influencing Return-to-Work of People with Depression in (2009) by M. Corbière, M. J. Durand, M. F. Coutu, L. St-Arnaud, T. Lecomte. The project is funded by CIHR and IRSST.) Other questions (open) were developed by the committee. Three people with a mental disorder tested the questionnaire before data collection to ensure the clarity of the questions.

The results presented in this paper relate to one openended question of the survey, that is, the strategies used by respondents to reduce prejudice and stigma toward people with a diagnosis of mental disorder. The question was worded as follows: tell us briefly what you do to reduce prejudice and stigma toward people with a diagnosis of mental disorder.

2.3. Participants. Every conference delegate was eligible to participate in the study. Of the 801 delegates, 315 agreed to answer the questionnaire. (Please note that it is not possible to establish a precise response rate because the conference was held on 3 days (November 8-9-10, 2010) and data collection was done at the beginning of the conference, at which time not all delegates were present.) A total of
277 people answered the question specific to this paper: 121 (44\%) were clinicians/professionals and 74 (27\%) were users of mental health services. The other types of respondents each comprised $10 \%$ or less of the participants: managers $(10 \%)$, coordinators $(8 \%)$, professors-researchers/research professionals/teachers (3\%), parents/friends (3\%), students $(1 \%)$, and other $(4 \%)$. Our sample included 183 women (71\%). Considering the whole sample, 168 respondents $(62 \%)$ held a university degree, nearly a quarter (24\%) had a college degree, and (14\%) had a high school diploma or less. The age groups of the respondents included 154 (56\%) people between 35 and 54, with the remaining respondents either under $35(21 \%)$ or over $54(23 \%)$.

2.4. Data Analyses. The authors (M. Corbière and E. Samson) read the verbatim to get a general idea of the strategies mentioned by the respondents. After independently identifying categories of the strategies observed in the verbatim, the authors, together, established a final list of 15 categories of strategies, which excluded nonrelevant or incomprehensible references. The process of establishing categories reduced the number of selected respondents to 253 . Because the verbatim was generally simple and straightforward, the strategies mentioned by the respondents were easy to conceptualize. From this common list, the authors conducted categorization of all verbatim independently, then compared the category or categories(s) awarded by each of them to each transcript. The concordance rate for the categories between the authors was high, approximately $92 \%$. Disagreements between the two authors were mainly about categories of strategies that were close in content. For example, "I refuse to speak against people that have a mental disorder" was categorized as "reframing words" by one author and as "defending rights" by the other. These differences were discussed until a consensus was reached.

To distinguish whether the strategies used to fight social stigma differed between the respondents, the 15 categories of strategies obtained were grouped into six major themes inspired by the literature on the subject [23]. Three groups of respondents were also created, according to their type of knowledge: clinical, experiential, and organizational. Respondents matching the clinical knowledge profile were professionals and/or clinicians $(n=115)$ working with people with a mental disorder. People with an experiential knowledge profile were those who, in the survey, identified themselves as users of mental health services $(n=61)$; finally, those who worked in the field of mental health as directors/managers $(n=24)$ or coordinators $(n=22)$ fit the organizational knowledge profile. Since the percentage of other respondents (e.g., professors-researchers/research professionals/teachers $(n=8)$, parents/friends $(n=7)$, students $(n=2)$ was very low (lower than $4 \%$ each category), they were not considered for analyses. In the end, respondents with a profile that corresponded to the three targeted types of knowledge $(n=222)$ were included in comparison analyses. Figure 1 presents the number of retained respondents according to the different steps of the analysis. 


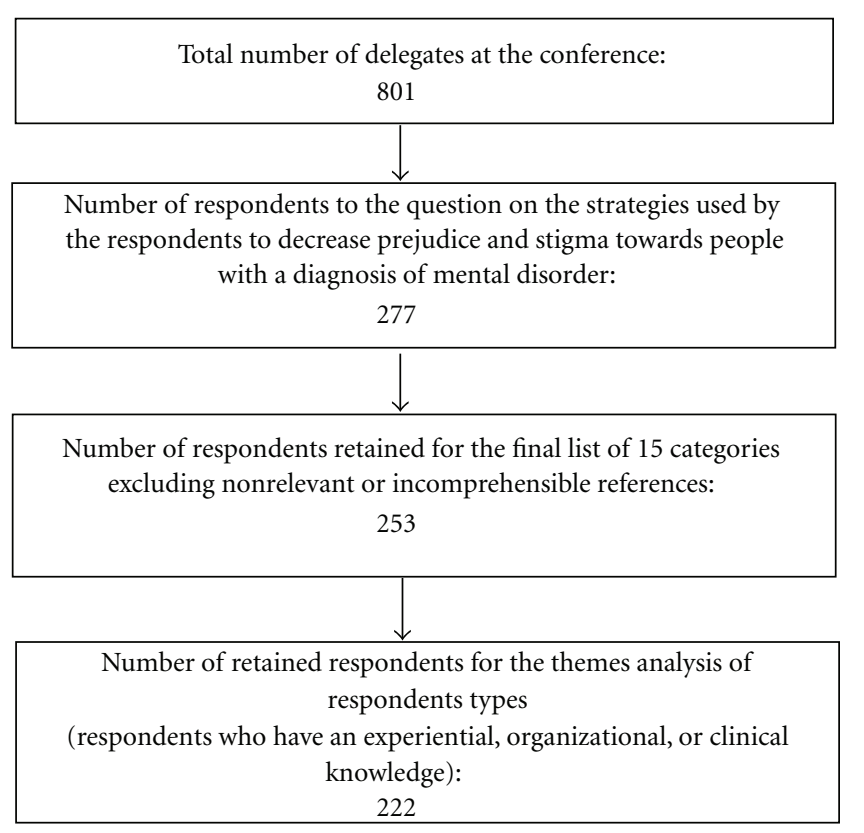

FIGURE 1: Number of respondents according to the different steps of the analysis.

\section{Results}

3.1. Part 1. As mentioned above, a first analysis of the results obtained from the 253 respondents whose entries to the question "Tell us briefly what you do to reduce prejudice and stigma toward people with a diagnosis of mental disorder" produced several strategies that were grouped into 15 categories. Table 1 shows the occurrence of each category. (The occurrence of each category is the result of dividing the number of respondents who gave a response associated with the category by the total number of respondents to the 15 categories (253). A given respondent may cite more than one strategy.)

We observed that the strategies used addressed not only the general population, but also the people directly concerned by the illness (AQRP conference delegates), which explains the particular nature of strategies used to fight stigma. Indeed, the strategies mentioned in this study can be viewed from three different perspectives depending on who the action targeted: the general population (e.g., educating/teaching); the person with a diagnosis (e.g., working on social inclusion); or the respondent himself (e.g., doing introspective work).

The most commonly mentioned type of strategy, Educating/teaching (42\%), is a strategy directed at the general population. It aims to inform people and to correct misconceptions with facts.

I downplay what presents itself and make people aware of what is mental health. I take this opportunity to explain what it can mean to the person, demystify what is happening and bring the person to understand what is happening. (Coordinator)
A third of the respondents (32\%) also mentioned strategies calling for normalizing. In most cases, normalizing was observed as a strategy directed at the person with a diagnosis. This meant treating or considering this individual the same as any other person, looking at that person the same way as anyone else, without any distinction related to the diagnosis, nor to a specific behaviour or opinion.

I act normal, I treat them like whole people and I ignore the illness. (Clinician/professional)

Having the same attitude, the same look as I have for others. (Clinician/professional)

In some cases, Normalizing was a strategy directed at the general population. People with a mental disorder were then presented to others as people who have the right to be different people. The notion of demystification was also present in this category.

I often tell people that mental health is very much like physical health [...] for me, treating mental health is the same as treating physical health, a good doctor with a good treatment, good will to want to recover. You can live in the community like everyone else. (User of mental health services)

These two strategies, Educating/teaching and Normalizing were the two main strategies mentioned by all respondents. Two other strategies also emerged: Working on Recovery (19\%) and Working on social inclusion (15\%)

I work as an occupational therapist in mental health among people with a diagnosis of mental disorder. I accompany them, help them realize their life plan based on their strengths and own difficulties. (Clinician/professional)

As a specialized mental health educator, it is part of my work to reduce prejudice by doing the most possible integration into the community with people with a mental health problem. (Clinician/professional)

These two strategies were directed at the person with a diagnosis. To work on recovery involved supporting, assisting, and encouraging the person. It was about believing in the person, building on his or her strengths and possibilities, rather than taking charge. The respondents identified these attitudes and behaviors as ways to reduce prejudice and stigma. The second strategy, Working on social inclusion, referred to promoting the integration of the person with a mental disorder in the community, for example, in terms of social activities, education, or employment.

Sharing/encouraging disclosure were strategies directed at the general population and were used by about one in ten respondents (9\%). This meant, for people with a diagnosis, disclosing their condition in appropriate circumstances or more formally sharing their story with the public. For people working with individuals with a diagnosis, it meant allowing them to share their story. 
TABLE 1: Categories of strategies used to reduce prejudice and stigma.

\begin{tabular}{|c|c|c|}
\hline \multirow[t]{2}{*}{ Categories } & \multicolumn{2}{|c|}{$\begin{array}{c}\text { All } \\
(n=253)\end{array}$} \\
\hline & $\%$ & Rank \\
\hline \multicolumn{3}{|l|}{ Educating/teaching } \\
\hline $\begin{array}{l}\text { I try to make people around me aware of prejudice whenever I get the chance by } \\
\text { explaining what mental health problems are. (Clinician/professional) }\end{array}$ & $42 \%$ & 1 \\
\hline \multicolumn{3}{|l|}{ Normalizing } \\
\hline $\begin{array}{l}\text { I think that people who receive a diagnosis are like everyone else and they } \\
\text { shouldn't be treated differently. (Clinician/professional) }\end{array}$ & $32 \%$ & 2 \\
\hline \multicolumn{3}{|l|}{ Working on recovery } \\
\hline $\begin{array}{l}\text { I help them to keep faith }[\ldots], \text { I work with their strengths and their } \\
\text { potentialities. I think with them, rather than taking charge of them or trying to } \\
\text { save them. (Coordinator) }\end{array}$ & $19 \%$ & 3 \\
\hline \multicolumn{3}{|l|}{ Working on social inclusion } \\
\hline $\begin{array}{l}\text { I work with mental health clients, I help them to "mingle" in society through } \\
\text { various activities. (Clinician/professional) }\end{array}$ & $15 \%$ & 4 \\
\hline \multicolumn{3}{|l|}{ Listening/caring } \\
\hline $\begin{array}{l}\text {. listening to them, welcoming them. (User of mental health services) } \\
\text { I place importance on what the person with the diagnosis thinks and expresses. } \\
\text { (Coordinator) }\end{array}$ & $11 \%$ & 5 \\
\hline
\end{tabular}

Sharing/encouraging disclosure

I share my story of mental illness. (User of mental health services)

Encouraging and supporting people with mental illness to disclose and share $\quad 9 \%$ their experiences. (Director/manager)

Accepting/respecting

I try not to judge these people. (User of mental health services)

Respecting their point of view, opinions on their needs and services received.

(Clinician/professional)

\section{Reframing words}

I insist that they not be called fools during meetings with others.

(Clinician/professional)

Giving successful examples

This can be done by showing specific examples of people who have come out of

the hospital and were able to live a normal life, like anyone else.

(Clinician/professional)

Doing introspective work

You have to be willing to address these issues, to confront yourself, with respect

to people with disabilities, to let go of ideas or imagination linked to ignorance.

(Clinician/professional)

Meeting/coming close to

I am close to people with mental health problems and these people are my

friends. (Parent/friend)

Defending rights

I campaign for the defence of mental health rights. (User of mental health services)

Acting on an organizational level

I am creating new recovery programs, representation at the health agency ... (Clinician/professional)

Being natural

I stay natural with everyone. (User of mental health services)

Paying attention to language

I remove inadequate vocabulary: - user; services user. Person first!

(Clinician/professional) 
I tell my story. (User of mental health services)

I disclose my illness to my employers despite prejudices. (User of mental health services)

Have people share their story in front of certain audiences. (Coordinator)

Other categories of strategies are listed in Table 1, three of which will be discussed here: listening/caring (11\%), accepting/respecting (8\%), and meeting/coming close to (3\%). These three categories of strategies were directed at the person with a diagnosis. It was interesting that the more the category of strategies involved a significant degree of proximity between the respondent and the person with a diagnosis, the less it was mentioned. Thus, while $11 \%$ of respondents mentioned that they listen, welcome, and take an interest in the person, and that $8 \%$ say they respect, accept, and do not judge the person, only 3\% mention meeting, coming close to the person, and making the person a friend, a spouse.

In addition, two other strategies deserve our attention despite their low incidence: doing introspective work (6\%) and being natural (2\%) were two self-directed categories of strategies. Doing introspective work involved focusing on personal prejudices, ignorance, and working to reduce selfstigmatization.

I learn to better understand their reality, to correct my perceptions. (Clinician/professional)

I don't stigmatise myself. (User of mental health services)

Conversely, the person with a mental disorder may also choose simply to act naturally (Being natural), without publicly disclosing his or her diagnosis. At first glance, this strategy may seem to contradict the notion of sharing. However, the person living with a diagnosis who is acting, day-to-day, like everyone else, without reference to diagnosis, symptoms, or treatments, for example, normalizes mental illness for those she/he meets. For example, the following is the verbatim of a respondent who identified herself as a user of mental health services:

I live with a diagnosis of mental disorder with being myself. Therefore I become a living model, and since it is not written on my forehead, my mental disorder is part of me and I do not think it is a nuisance. I do not feel compelled to tell everyone. To counter the prejudice and stigma, I chose to act like a person without distinction. (User of mental health services)

3.2. Part II. To determine if the nature of the strategies used varied among types of respondents, the authors placed the respondents into three groups according to their type of knowledge: clinical $(n=115)$, experiential $(n=61)$, and organizational $(n=46)$, as defined above. In addition, the 15 categories of strategies identified initially were grouped under six main themes: education, contact, protestation, person centered, working on recovery and social inclusion, and Reflective consciousness, as presented in Table 2.

The themes Education, Contact, and Protestation were inspired by the literature on the subject and they refer to three proven strategies to fight stigma [23, 33]. The theme Education aims to reduce stigma by providing accurate information about mental disorders. The strategies within this theme rest on the assumption that a better understanding of mental disorders will cause people to reduce their prejudices and act in a nondiscriminatory manner toward individuals who live or has lived with a mental disorder [34]. The theme Contact promotes positive interpersonal interactions between a person who has or have lived with a mental disorder (who disclosed his/her condition) and a member of the public; living libraries are an example of the application of this strategy $[35,36]$. (Organized in a public place, the living libraries allow the public to "borrow" time (30 min) from a person who has or had a mental disorder and have a conversation with her.) The theme Protestation addresses inappropriate or negative representations of mental illness used by the public or media by denouncing them. Some authors include the strategies used by organizations for the defense of rights in the strategies of protestation [37], while others see them as a separate strategy [22].

In the context of this study, the theme Education includes strategies from the following categories: Educating/teaching, giving successful examples, acting on an organizational level and paying attention to language. Contact refers to the strategies that correspond to the categories Sharing/encouraging disclosure and Meeting/coming close to. Protestation is the theme for defending rights and reframing words.

In addition to these three themes of strategies directly inspired by the scientific literature, this study, which was aimed at people related to the mental health field, has identified three additional major themes of strategies: person centered, working on recovery and social inclusion and reflective consciousness. The theme Person centered implies treating the person with a mental disorder diagnosis as any other person (as seen above), but also accepting, respecting, listening to, and caring for the person. This last theme means to act without discrimination against a person with a mental disorder, to welcome that person like anyone else; it is to have speech and values that place the individual as a whole person, beyond diagnosis. The theme Working on recovery and social inclusion implies the idea of supporting and encouraging the person, believing in him/her, building on his/her strengths and possibilities, and fostering his/her integration into the community. The theme of Reflexive consciousness refers to Doing introspective work and Being natural. The strategies related to this theme imply a return to oneself. Based on these six broad themes of strategies to fight stigma, Figure 2 highlights the percentages of the three groups of people according to their type of knowledge: experiential, organizational, and clinical.

Figure 2 shows some important distinctions in the strategies used by the three groups of respondents in the study. People with experiential knowledge were easily distinguished from the other two groups. First, they were less likely to have 
TABLE 2: Themes and corresponding categories of strategies.

\begin{tabular}{ll}
\hline Theme & Categories of strategies \\
\hline Education & $\begin{array}{l}\text { Educating/teaching } \\
\text { Giving successful examples } \\
\text { Acting on an organizational level } \\
\text { Paying attention to language }\end{array}$ \\
\hline Contact & $\begin{array}{l}\text { Sharing/encouraging disclosure } \\
\text { Meeting/coming close to }\end{array}$ \\
\hline Protestation & $\begin{array}{l}\text { Defending rights } \\
\text { Reframing words }\end{array}$ \\
\hline Person centered & $\begin{array}{l}\text { Normalizing } \\
\text { Accepting/respecting } \\
\text { Listening/caring }\end{array}$ \\
\hline $\begin{array}{l}\text { Working on } \\
\text { recovery and } \\
\text { social inclusion }\end{array}$ & Working on recovery \\
\hline $\begin{array}{l}\text { Reflexive } \\
\text { consciousness }\end{array}$ & Working on social inclusion \\
\hline
\end{tabular}

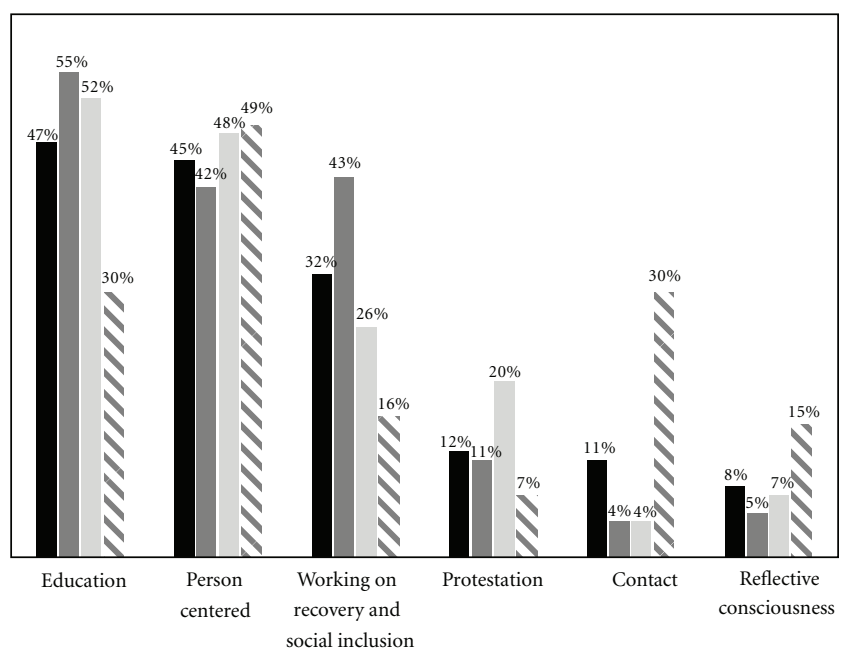

all

- Organizational knowledge

Clinical knowledge

- Experiential knowledge

FIGURE 2: Types of strategies (themes) according to the respondents' type of knowledge.

mentioned a strategy related to the theme Education (30\% versus $55 \%$ and $52 \%$ for those with clinical knowledge and organizational knowledge, resp.). Second, they were more likely to have mentioned strategies related to the theme of Contact (30\% versus $4 \%$ for those with a clinical profile or organizational). People with clinical knowledge mentioned strategies like Working on recovery and social inclusion more often than those with organizational knowledge and experiential knowledge ( $43 \%$ versus $26 \%$ and $16 \%$, resp.). In addition, the theme of Person centered was a strategy widely used by the three groups studied: nearly half (between $42 \%$ and $49 \%$ ) mentioned it. Strategies grouped under the themes of Protestation and Reflexive consciousness were less cited by these three groups (between 5\% and 20\%). Figure 2 shows that, compared to the other two groups, the experiential knowledge group tended to mention more strategies in connection with the theme Reflexive consciousness (15\% versus $5 \%$ and $7 \%$ ).

\section{Discussion}

The objective of this study was to describe the strategies used by different stakeholders to fight social stigma toward people with a mental disorder. This study is interesting on two levels. First, it was specifically aimed at people connected to mental disorders (e.g., people with a mental disorder, mental health professionals). Second, the strategies identified were, with few exceptions, strategies used individually and spontaneously in everyday life, while studies from the specialized literature almost always report strategies used in structured programs or initiatives [38-41].

From the Canadian conference delegates who answered to the question Tell us briefly what you do to reduce prejudice and stigma toward people with a diagnosis of mental disorder, the study identified 15 categories of strategies to fight stigma (e.g., Reframing words, Working on recovery). These results underline the creativity of diverse groups of people implementing various strategies to fight social stigma on a daily basis. To our knowledge, few studies have provided these types of results, and this illustrates the importance of consulting different stakeholders to capture the richness and range of opportunities. Indeed, we identified particular categories of strategies rarely cited, such as those relating to Being natural or Doing introspective work, which display the importance of introspective work for the individual in fighting stigma.

To compare the different stakeholders based on their knowledge-that is, experiential (users of mental health services), organizational (directors, managers, or coordinators working in the field of mental health), and clinical (mental health professionals and/or clinicians)—the 15 previous categories were grouped into six broad themes: Education, Protestation, Contact, Person centered, Working on recovery and social inclusion, and Reflexive consciousness. As noted in the introduction, the first three themes, Education, Protestation, and Contact, were inspired by the literature on the subject; they refer to three widely recognized strategies to fight stigma [22, 33]. Education strategies are very popular because they are readily available to the public, in the case of campaigns, or transferred from one organization to another, in the case of more or less long-term education and awareness programs $[23,39]$. Protestation strategies aim to reduce stigma by denouncing inaccurate messages. The concepts of testimony and disclosure are also very present in the literature on mental illness stigma. We refer here to the strategy of Contact that encourages interactions between a person with a mental disorder and a member of the general public [27].

The other three major themes that emerged from this study were the strategies of Person centered, Working on recovery and social inclusion, and Reflexive consciousness. Strategies within the theme Person centered, used in large proportion (50\%) by all types of respondents, are similar to an approach described by Davidson [42] which states that one way to 
fight stigma toward people living with a mental disorder is to modify the elements that contribute to identifying them, through the eyes of the general population, as people with a mental disorder. The strategies grouped under the general theme Working on recovery and social inclusion refer to the psychosocial movement of rehabilitation in psychiatry linked with the (re)construction of personal identity $[42,43]$. The concept of recovery is based on the hopefulness of a better life, both inside and outside the network of mental health. These new avenues for the recovery of the individual share the concerns and values of current psychiatric rehabilitation [44]. Reflective consciousness strategies are reminiscent of the principles from the reflective approach (or reflection). Reflective consciousness is generally defined as a process by which a person reflects and attempts to restructure one's experience and/or knowledge and, consequently, to deal with attitudes and behaviours as objects of observation-in this case toward the social stigma against people with a mental disorder.

The three major themes of the literature-inspired strategies to fight stigma can have both positive and negative results. While Education can help to change attitudes, the magnitude and duration of these changes may be limited [23]. Stuart [34] also emphasized that it is very likely that massive public education campaigns may be weak or ineffective as a contributor to changes in attitudes and behaviors. It has been generally observed that although Protestation strategies may remove certain media messages detrimental to people with a mental disorder at the individual level, they can also cause a "rebound" effect, reinforcing the behaviour we wish to eliminate. People targeted by the protest may have the opposite of the intended reaction because nobody likes to be told what to do, say, or think $[23,45]$. It has been observed that when the general population interacts with a person with a mental disorder as part of an antistigma program, Contact strategy may result in significant improvements in attitude. Moreover, changes in attitudes resulting from these contacts are maintained through time and are related to changes in behavior [2]. The results obtained in this study show that a much higher proportion of respondents with experiential knowledge (those who live or have lived with a mental disorder) use Contact strategies to fight against stigma than do respondents with clinical or organizational knowledge. Those with clinical or organizational knowledge can be distinguished from those with experiential knowledge by the former's use of Education strategies. Note that the Contact strategy implicitly involves the concept of disclosure. According to Corrigan and O’Shaughnessy [23], a way to massively increase the power of contact is to encourage people with mental disabilities to disclose their experience. Those who actually do disclose their experience can contribute significantly to fighting stigma. However, some disadvantages can be associated with disclosure: social avoidance by people who know and discrimination in employment or housing. Thus, it is hardly surprising that a few respondents with clinical or organizational knowledge have cited encouraging disclosure as a strategy they use to reduce stigma, given the disadvantages their clients could encounter.
Strategies within the theme Person centered create physical or relational environments that enable a person to begin the process of reconstruction of citizenship identity through the development of interconnectedness capacities, therefore gradually becoming an integral part of society [46]. This theme is intimately linked to the theme of Working on recovery and social inclusion. Thus, it is no surprise that people with clinical knowledge make significant use of both Person centered and Working on recovery and social inclusion in similar proportions (42-43\%) since their work is based on social inclusion and recovery of people with mental disorders, as well as to help them attain full citizenship [47]. Conversely, adopting Doing introspective work or Being natural strategies, from the general theme of Reflexive consciousness, allows better development of selfknowledge and, therefore, helps the individual to adopt behaviours and attitudes that are closer to social inclusion or even destigmatization.

Based on the results of this study, the theme Contact has emerged as an important strategy for people with a mental disorder diagnosis. Given that the literature emphasizes its efficiency to combat social stigma, it is important to better understand the phenomenon of disclosure because it is a key element in the fight against stigma. Several interesting questions arise: what is the experience of people who have disclosed their mental condition? What advantages and disadvantages have they experienced? what are the reasons why some people are not afraid to disclose their condition? Are there beneficial conditions that allow or promote disclosure (e.g., security acquired in housing, employment, social network)? Some of these questions are already answered in the literature. For example, some studies show that disclosure in the workplace has the advantage of ridding the individual of the stress inherent in hiding one's mental disorder, among others, and creates the possibility of requesting work accommodations $[48,49]$. Disadvantages can include being at risk of being treated differently and reducing professional opportunities [49]. During the development of programs to fight stigma using a Contact strategy, it is important to be well informed about and to consider the factors surrounding disclosure in order to fully support people who decide to disclose their mental disorder. This knowledge is also important for staff working with people with a mental disorder to help them better support those who voluntarily wish to disclose their mental disorder. Currently, the stigma of mental illness is a major barrier to disclosure: according to the Quebec Ministry of Health and Social Services, 42\% of people struggling with a mental health problem have not told their family for fear of being judged [50]. Moreover, according to a Canadian Medical Association report [51], only half of Canadians would tell their friends or colleagues if a family member was diagnosed with mental illness (50\%), compared to a wide majority that would speak of a cancer diagnosis $(72 \%)$ or diabetes $(68 \%)$ in the family. Disclosure (or testimony) and stigma are highly correlated: the more people with mental disorders willingly talk about their condition, the less mental illness will be stigmatized and the more people with a mental disorder will be inclined to disclose their condition. 
Some of the published literature notes the importance of working with health professionals to reduce the stigma faced by people with a mental disorder when they receive services [52]. The strategies adopted here by people with clinical knowledge can certainly serve as clues to guide these professionals in their contacts with people with a mental disorder. This refers to Person centered and Working on recovery and social inclusion. By paying attention to the whole person, beyond the diagnosis and symptoms, as implied by a recovery-based approach, a health care professional could avoid falling into the trap of diagnostic overshadowing, which has adverse consequences for people with a mental disorder. Thornicroft [35] explains that because of their diagnosis, people with mental illness are less likely to receive adequate health care from the health professionals than people who do not have this type of disease: examinations are less thorough, treatments are less complete, and the service offer for these people is diminished.

This study has some limitations. First, it identifies strategies to fight stigma used by various groups of people connected to mental disorders but it does not assess the effectiveness of these strategies. If the strategies of Education, Protestation, and Contact are well documented in relation to their effectiveness in fighting stigma, those that emerged in this study would benefit from being evaluated, including strategies of Person centered and Working on recovery and social inclusion, as well as Reflexive consciousness.

It is also important to note that this study used a sample of individuals concerned with the subject, who, by their presence at the conference, were immersed in an environment where stigma against people with a mental disorder was clearly denounced (recall the title of the symposium: Overcoming Stigma, a Collective Challenge!). This limit may also be an asset: highly aware of and sensitive to the topic, respondents were probably better able to identify the strategies they personally use to combat the social stigma against those with a diagnosis of mental disorder.

In conclusion, this study aimed to provide a thorough and exhaustive perspective on the whole range of strategies to fight stigma used by different stakeholders. Several categories of strategies emerged from the verbatim, which were organized into six main themes: Education, Contact, Protestation, Person centered, Working on recovery and social inclusion, and Reflexive consciousness. Some strategies were used more often than others by specific stakeholders. Furthermore, the notion of disclosure of mental disorders emerged as a key factor for fighting stigma. Future studies will allow us to assess the impact of these strategies on various settings, such as health, community, workplace, and school.

\section{Conflict of Interests}

The authors declare that there is no conflict of interests.

\section{Acknowledgments}

The authors would specifically like to thank the conference delegates who took part in this study, as well as Diane Harvey,
Claude Charbonneau, Rosalie Bérubé, Karine Genest, and the research assistants who helped along the way. These results were in part presented during the last day of the 15th conference entitled "Overcoming Stigma, a Collective Challenge!" in order to provide a feedback to participants.

\section{References}

[1] World Health Organization, "Mental mealth: new understanding, new hope," The World Health Report, World Health Organization, Geneva, Switzerland, 2001.

[2] P. W. Corrigan and A. K. Matthews, "Stigma and disclosure: implications for coming out of the closet," Journal of Mental Health, vol. 12, no. 3, pp. 235-248, 2003.

[3] I. D. Rutman, "How psychiatric disability expresses itself as a barrier to employment," Psychosocial Rehabilitation Journal, vol. 17, no. 3, pp. 15-35, 1994.

[4] E. Goffman, Stigma: Notes on the Management of Spoiled Identity, Prentice Hall, Englewood Cliffs, NJ, USA, 1963.

[5] C. Lauber, "Stigma and discrimination against people with mental illness: a critical appraisal," Epidemiologia e Psichiatria Sociale, vol. 17, no. 1, pp. 10-13, 2008.

[6] H. Stuart, "Stigma and work," Healthcare Papers, vol. 5, no. 2, pp. 100-111, 2004.

[7] B. Everett, "Stigma the hidden killer. Mood disorders society of Canada," 2006, http://www.mooddisorderscanada.ca/documents/Publications/Stigma_and_discrimination_as_expressed by_MH_Professionals.pdf.

[8] M. Charbonneau, "Stigma and discrimination-as expressed by mental health professionals," Research Report, Mood Disorders Society of Canada, 2007.

[9] P. W. Corrigan and P. Kleinlein, "The impact of mental illness stigma," in On the Stigma of Mental Illness, P. W. Corrigan, Ed., pp. 11-44, American Psychological Association, Washington, DC, USA, 2005.

[10] J. Evans and J. Repper, "Employment, social inclusion and mental health," Journal of Psychiatric and Mental Health Nursing, vol. 7, no. 1, pp. 15-24, 2000.

[11] M. C. Angermeyer, B. Schulze, and S. Dietrich, "Courtesy stigma-a focus group study of relatives of schizophrenia patients," Social Psychiatry and Psychiatric Epidemiology, vol. 38, no. 10, pp. 593-602, 2003.

[12] W. Gaebel, A. E. Bauman, and H. Zaske, "Intervening in a multi-level network: progress of the German open the doors projects," World Psychiatry, vol. 4, supplement 1, pp. 16-20, 2005.

[13] D. Sadow and M. Ryder, "Reducing stigmatizing attitudes held by future health professionals: the person is the message," Psychological Services, vol. 5, no. 4, pp. 362-372, 2008.

[14] D. Caltaux, "Internalized stigma: a barrier to employment for people with mental illness," International Journal of Therapy and Rehabilitation, vol. 10, pp. 539-543, 2003.

[15] B. Hocking, "Reducing mental illness stigma and discrimination-Everybody's business," Medical Journal of Australia, vol. 178, no. 9, pp. S47-S48, 2003.

[16] P. Byrne, "Psychiatric stigma," The British Journal of Psychiatry, vol. 178, no. 3, pp. 281-284, 2001.

[17] J. C. Phelan, B. G. Link, and J. F. Dovidio, "Stigma and prejudice: one animal or two?" Social Science and Medicine, vol. 67, no. 3, pp. 358-367, 2008.

[18] H. Stuart, "Why stigma matters and why it shoudl be beaten," World Psychiatry, vol. 4, supplement 1, pp. 6-7, 2005. 
[19] C. Buizza, B. Schulze, E. Bertocchi, G. Rossi, A. Ghilardi, and R. Pioli, "The stigma of schizophrenia from patients' and relatives' view: a pilot study in an Italian rehabilitation residential care unit," Clinical Practice and Epidemiology in Mental Health, vol. 3, pp. 23-30, 2007.

[20] R. Persaud, "Psychiatrists suffer from stigma too," Psychiatric Bulletin, vol. 24, no. 8, pp. 284-285, 2000.

[21] D. Wilkinson and J. Daoud, "The stigma and the enigma of ECT," International Journal of Geriatric Psychiatry, vol. 13, no. 12, pp. 833-835, 1998.

[22] J. Arboleda-Florez, "Stigma and discrimination: an overview," World Psychiatry, vol. 4, supplement 1, pp. 8-10, 2005.

[23] P. W. Corrigan and J. R. O'Shaughnessy, "Changing mental illness stigma as it exists in the real world," Australian Psychologist, vol. 42, no. 2, pp. 90-97, 2007.

[24] P. W. Corrigan, P. P. River, R. K. Lundin et al., "Three strategies for changing attributions about severe mental illness," Schizophrenia Bulletin, vol. 27, no. 2, pp. 187-195, 2001.

[25] J. L. Wang, "Mental health literacy and stigma associated with depression in working performance," in Work Accommodation and Retention in Mental Health, I. Z. Shchultz and E. S. Rogers, Eds., pp. 341-351, Springer, New York, NY, USA, 2011.

[26] N. Rüsch, M. C. Angermeyer, and P. W. Corrigan, "Mental illness stigma: concepts, consequences, and initiatives to reduce stigma," European Psychiatry, vol. 20, no. 8, pp. 529539, 2005.

[27] P. W. Corrigan and D. L. Penn, "Lessons from social psychology on discrediting psychiatric stigma," American Psychologist, vol. 54, no. 9, pp. 765-776, 1999.

[28] S. Van der Meij and M. Heijnders, "The fight against stigma: stigma reduction strategies and interventions," in Proceedings of the International Stigma Workshop, Soesterberg, The Netherlands, November 2004.

[29] M. R. Islam and M. Hewstone, "Dimensions of contact as predictors of intergroup anxiety, perceived out-group variability, and out-group attitude: an integrative model," Personality and Social Psychology Bulletin, vol. 19, no. 6, pp. 700-710, 1993.

[30] M. E. Kolodziej and B. T. Johnson, "Interpersonal contact and acceptance of persons with psychiatric disorders: a research synthesis," Journal of Consulting and Clinical Psychology, vol. 64, no. 6, pp. 1387-1396, 1996.

[31] S. M. Couture and D. L. Penn, "Interpersonal contact and the stigma of mental illness: a review of the literature," Journal of Mental Health, vol. 12, no. 3, pp. 291-305, 2003.

[32] K. Catthoor, M. De Hert, and J. Peuskens, "Stigma and schizophrenia. a review," Tijdschrift voor Psychiatrie, vol. 45, no. 2, pp. 87-95, 2003.

[33] P. W. Corrigan and A. Wassel, "Understanding and influencing the stigma of mental illness," Journal of Psychosocial Nursing and Mental Health Services, vol. 46, no. 1, pp. 42-48, 2008.

[34] H. Stuart, "Stigmatisaition Leçons tirées des programmes visant sa diminution," Santé mentale au Québec, vol. 28, no. 1, pp. 54-72, 2003.

[35] G. Thornicroft, "Evidence of how to reduce stigma and discrimination. Summary of the conference given by Dr. Graham Thornicroft at the $\mathrm{XV}^{\mathrm{e}}$ Colloque de l'Association québécoise pour la réadaptation sociale," Summary by Esther Samson and Yves Blanchette. 2010, http://www.aqrpsm.org/colloque/resumes/xve/ouverture_xve_thornicroft-re sume-fr.pdf.
[36] L. Loubières and A. Caria, "La bibliothèque vivante: un outil de lutte contre la stigmatisation en santé mentale," La santé de l'homme, no. 413, pp. 23-24, 2011.

[37] R. M. Kowalski and M. R. Leary, The Interface of Social and Clinical Psychology: Key Readings, Psychology Press, 2004.

[38] A. Rosen, G. Walter, D. Casey, and B. Hocking, "Combating psychiatric stigma: an overview of contemporary initiatives," Australasian Psychiatry, vol. 8, no. 1, pp. 19-26, 2000.

[39] P. W. Corrigan, "Target-specific stigma change: a strategy for impacting mental illness stigma," Psychiatric Rehabilitation Journal, vol. 28, no. 2, pp. 113-121, 2004.

[40] H. Stuart, "Fighting the stigma caused by mental disorders: past perspectives, present activities, and future directions," World Psychiatry, vol. 7, no. 3, pp. 185-188, 2008.

[41] P. Corrigan and B. Gelb, "Three programs that use mass approaches to challenge the stigma of mental illness," Psychiatric Services, vol. 57, no. 3, pp. 393-398, 2006.

[42] M. Davidson, "What else can we do to combat stigma?" World Psychiatry, vol. 1, no. 1, pp. 22-23, 2002.

[43] S. Noiseux and N. Ricard, "Le rétablissement des personnes vivant avec la schizophrénie," Perspective Infirmière, vol. 3, no. 2, pp. 10-20, 2005.

[44] M. Farkas and W. A. Anthony, "Psychiatric rehabilitation interventions: a review," International Review of Psychiatry, vol. 22, no. 2, pp. 114-129, 2010.

[45] M. J. Monteith, J. W. Sherman, and P. G. Devine, "Suppression as a stereotype control strategy," Personality and Social Psychology Review, vol. 2, no. 1, pp. 63-82, 1998.

[46] N. C. Ware, K. Hopper, T. Tugenberg, B. Dickey, and D. Fisher, "Connectedness and citizenship: redefining social integration," Psychiatric Services, vol. 58, no. 4, pp. 469-474, 2007.

[47] M. Rowe, A. Clayton, P. Benedict et al., "Going to the source: citizenship outcome measure development," Psychiatric Services, vol. 63, no. 5, pp. 445-450, 2012.

[48] M. L. Ellison, Z. Russinova, K. L. MacDonald-Wilson, and A. Lyass, "Patterns and correlates of workplace disclosure among professionals and managers with psychiatric conditions," Journal of Vocational Rehabilitation, vol. 18, no. 1, pp. 3-13, 2003.

[49] K. L. MacDonald-Wilson, "Managing disclosure of psychiatric disabilities to employers," Journal of Applied Rehabilitation Counseling, vol. 36, no. 4, pp. 11-21, 2005.

[50] Ministère de la Santé et des Services sociaux, "Réponses du questionnaire Santé mentale: distinguer le vrai du faux," 2012, http://www.msss.gouv.qc.ca/sujets/prob_sante/sante_mentale/ index.php?aid=6\&print $=1$.

[51] Canadian Medical Association, "8th Annual National Report Card on Health Care," Canadian Medical Association, 2008.

[52] S. Lassonde and M. Pietrus, "La stigmatisation et la santè mentale: abattre le dernier tabou," Quintessence, vol. 3, no. 4, pp. 1-2, 2011. 


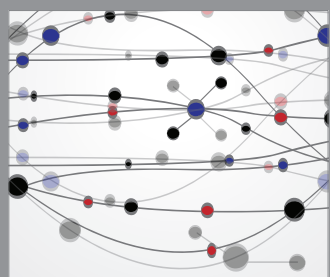

The Scientific World Journal
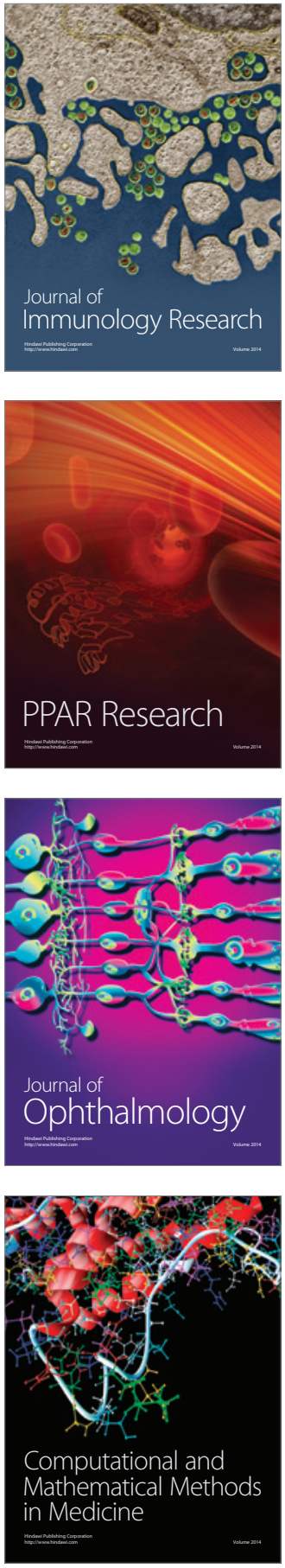

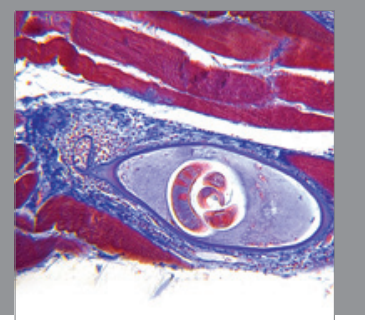

Gastroenterology

Research and Practice
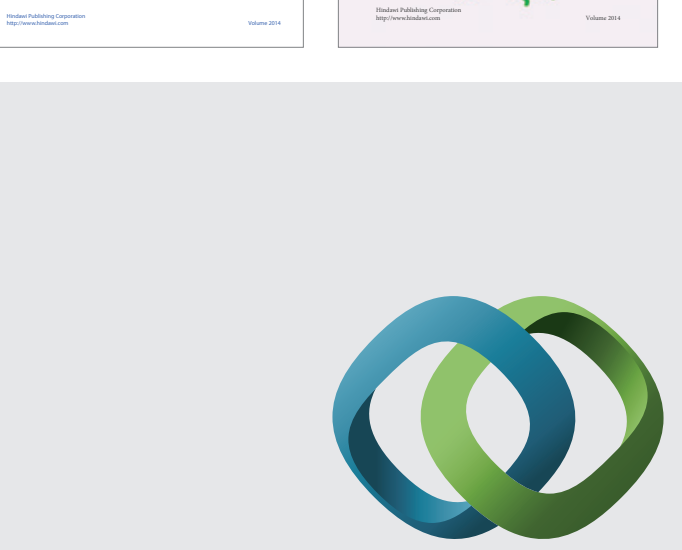

\section{Hindawi}

Submit your manuscripts at

http://www.hindawi.com
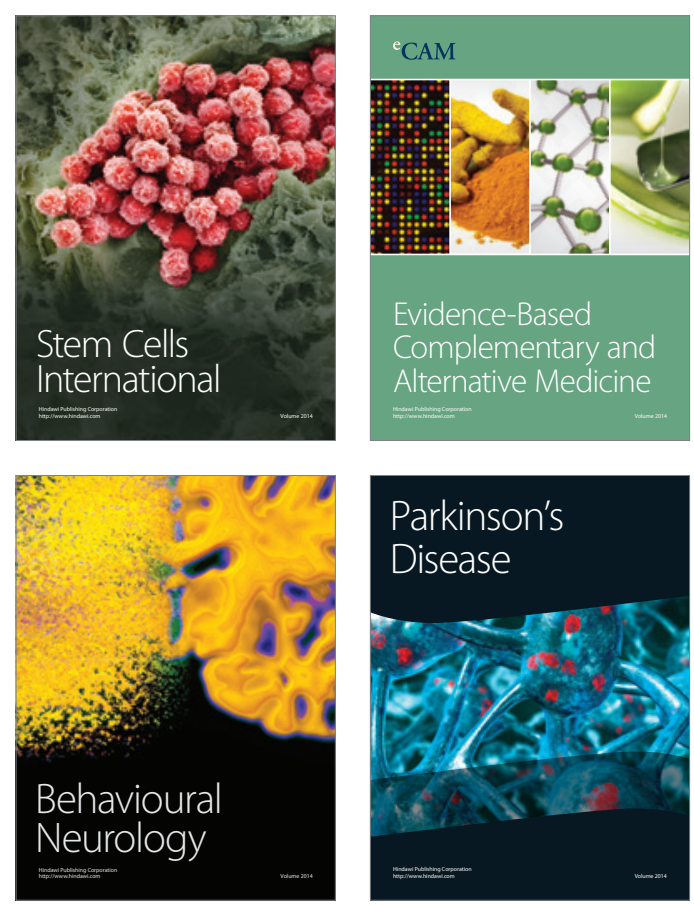

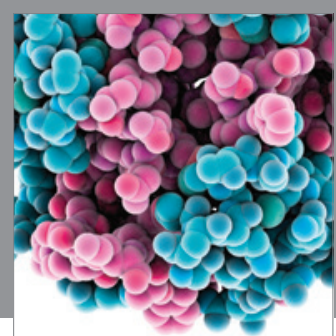

Journal of
Diabetes Research

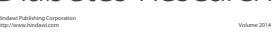

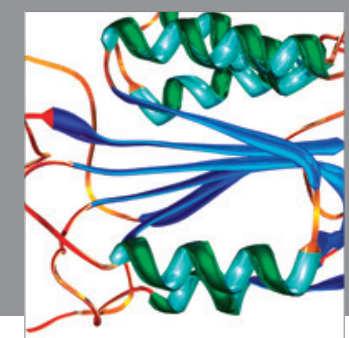

Disease Markers
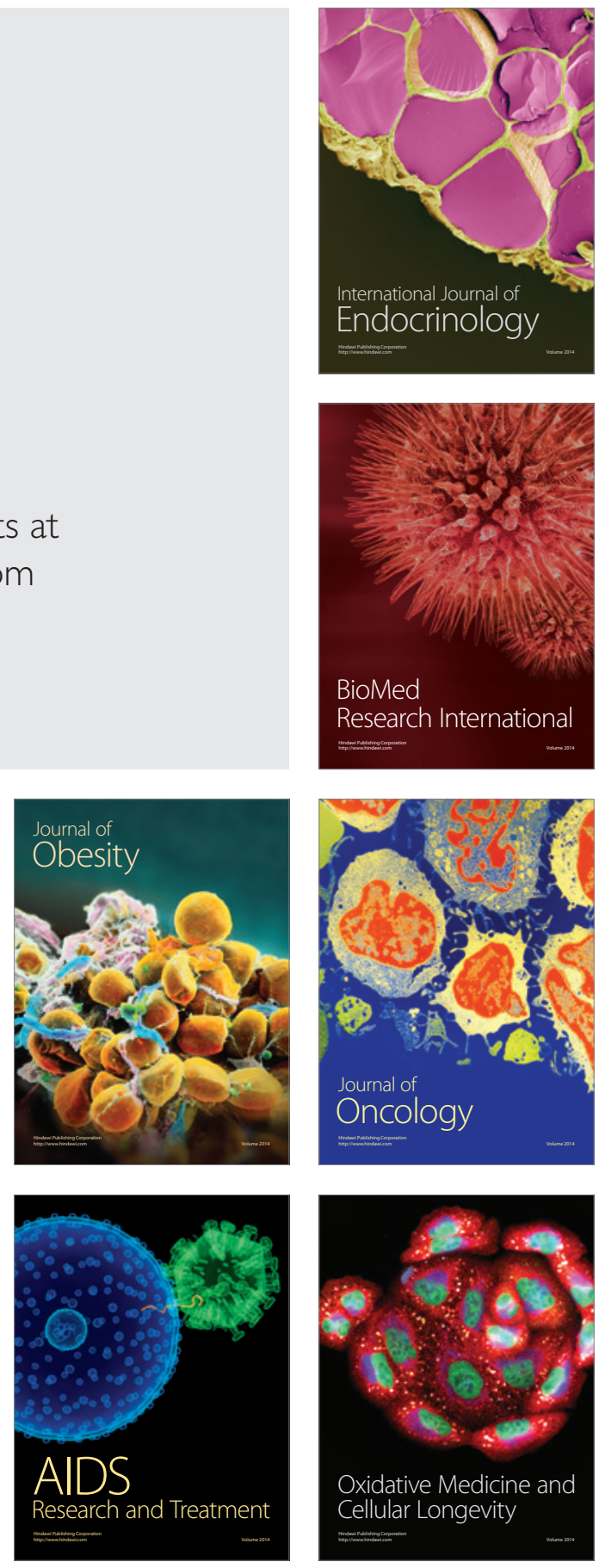